\title{
APPLYING FUZZY QFD MCDM TO EVALUATE MUSICAL INSTRUMENTS
}

\author{
Peter Poon Chong ${ }^{1 *}$ and Terrence R.M. Lalla ${ }^{2}$ \\ ${ }^{1,2}$ Faculty of Engineering, The University of the West Indies, Trinidad \\ ${ }^{1}$ Email: peter.poonchong@ $@$ sta.uwi.edu * (Corresponding author) \\ ${ }^{2}$ Email: terrence.lalla@sta.uwi.edu
}

\begin{abstract}
This paper exhibits a method to improve the quality of musical instruments with the application of two Multi-Criteria Decision Making models, Technique of Order Preference by Similarity to Ideal Solution (TOPSIS) and Analytic Hierarchy Process (AHP) in a Quality Function Deployment (QFD) Environment. A fuzzy analysis approach was also included to accommodate qualitative data in music. The QFD was constructed with literature based on optimizing the manufacture of musical instruments. At this phase of the research, the paper focused on the physical parameters and perceived qualities of musical instruments. The proposed modified QFD was developed to identify the product features chosen by the market and aid the manufacture of musical instruments. A standard QFD recognized and scored factors to develop and manufacture musical instruments. It accommodated some core engineering variables for the musical instruments but overlooked some feature stakeholder needs. For example, the musician may not have $100 \%$ gratification while playing the instrument as the manufacturer fails to capture acoustic features to psychologically satisfy the musician's audience. Using fuzzy logic, QFD and MCDM increased the model performance by expanding the data set. It offered the manufacturer of musical instruments a mode to capture and analyse behavioural linguistic data covering more customer requirements. Hence, the approach increased the range to correlate the physical features and psychological behaviours of musical instruments. It allowed non-technical persons to provide an improved form of reliable information. This modified QFD can also be applied to develop other products involving linguistic data.
\end{abstract}

Keywords: QFD, Fuzzy Logic, MCDM, TOPSIS, AHP, Linguistic Data, Musical Instrument Design

https://doi.org/10.47412/BGMJ4037

\section{Introduction}

The quality of a musical instrument is subjective in a multitude of dimensions. It is difficult to develop specifications of the instrument from data collected with musicians, manufacturers, and entrepreneurs in the industry. Individuals usually assess an instrument by a variety of factors divided between physical interactions and psychological developments [1]. The traditional QFD framework is a tool used to identify the product design requirements to increase the level of satisfaction based on rational market desires [2]. Inclusion of psychological data from behavioural patterns is necessary but conforming persons differentiated by collected experiences and beliefs develop an anomaly. Its data can be complex, vague and difficult to represent in a crisp form but can be gathered linguistically in the absence of specific cognitive details. Multi-Criteria Decision-Making methods introduce a solution by capturing and scaling behavioural responses identified within a customer's psychological aspirations [3]. It is proposed to take the technologically uncertain and uncontrollable psychological attributes and apply a fuzzy set theory to 
convert the data into a crisp form. Then converge the physical and converted psychological data collected for the musical instrument (both in the crisp form) in a QFD framework for decision-making [4].

\section{Literature Review}

For the proceedings of this paper, a musical instrument will be simply defined as a device created or modified to produce controlled sounds having rhythm, melody, or harmony [5]. A musical instrument may also be multidimensional with a variety of interpretations based on the person's experience and background. Other meanings may include and not be limited to items defined by its application, expression, cultural/historic purpose, and design [6]. There are five (5) organological categories for musical instruments [7]. The following describes each category:

- Idiophones- the sound is formed by the vibrations solely through the instrument's body

- Membranophones- the sound is developed by the vibrations of a tensioned membrane

- Chordophones- the sound is established by the vibrations of a tensioned string

- Aerophones- the sound is created by constrained vibrating air

- Electrophones- the sound is sourced from signals built electronically

\subsection{Quality of Musical Instruments}

Philosophers and scientists have studied musical sound and its sources since the times of the Ancient Greeks. This falls under the umbrella of musical acoustics and involves the physical properties of the musical sound and its sources; the transmission of sound from the instrument to the receiver; and the psychoacoustics of musical sound perception [8]. An audience differentiates musical sounds perceptually by describing its pitch, loudness, duration, and timbre attributes. The application of music signalling technology easily allows the quantification of the physical parameters of these attributes for further analysis [9]. The attributes depend on pressure, frequency, spectrum, duration measured and envelope. Another group of engineers and natural scientists refer to the quality of a musical instrument with its tones. The physical parameters of a tone can involve intensity, spectrum, duration measured, onset and decay transients comprised of subjective and objective characteristics. This is consistent with the previous description, except it focuses on the shape of the transients that form the envelope. They also considered non-acoustic attributes perceived through the value from famous builders, antique instruments and aesthetics. An ergonomic design also strengthens the instrument considering the performer's comfort, ease to reach the full dynamic range of the instrument and acceptance to display conscious or unconscious motions for the audience.

An instrument's musical consonance is perceived from a physical influence responding from the loudness, roughness, and sharpness reactions as the notes are excited. Musical dissonance which may be cantered on an individual or combined factors of roughness is perceived as one tone derived from two merged tones and/or the spectral energy of a sound. These are sounds that leave a sense of displeasure and can vary from one individual to another [10]. The possibility of irritating features such as sounds generated by music and natural environmental responses are absent. For example, the roughness and harmony derived from music ideologies that oversee pitch associations in melodious and harmonica movements. It is strongly believed that consonance physically detected precedes the appraisal of solitary chords, where harmony is impartial to the human response. The basic auditory mechanism triggers perceptual cauterization of harmonic intervals as consonant or dissonant and musical consonance can then be structured using both physiological and psychological behaviours. It expands the hierarchy based on the inclusion of harmony as a psychologic component and 'tonalness' as the degree of sound can be considered a tone or a noise [11].

The inclusion of harmony includes the principle organizational understanding and acoustic effects of music plausible to the ear and not to be mixed with a melody that is a succession of tones [10]. Generally, 
psychological and musical references to the term consonance and dissonance have a similar meaning. Consonance means pleasant, acceptable and constant versus dissonant meaning unacceptable, unpleasant and confused. The auditory system that rules harmonic perception comprises properties where a specific volume of peripheral auditory neurons is required to solve temporal regularities in acoustic fine structures. Note intervals and chords are restrained by the biological threshold in accepted Western Music. It also includes the differential tuning of multiple neurons in the auditory system to assort the frequencies in the audible spectrum [11].

\subsection{Parameters of a Musical Instrument}

A great portion to design musical instruments involves controlling the physical parameters. Figure: 17, illustrates the links and interlinks of the physical impact on the instruments (parameters) quality. These physical impacts rely on supply pressure, speed, angle, and position to excite a note on the instrument [12]. Expression and Musicianship describe all non-acoustic values and include the impact developed through the psychoacoustic components of the audience and musician. It can be easily overshadowed by apparent technical features which may be an unconscious action in an instrument's development.

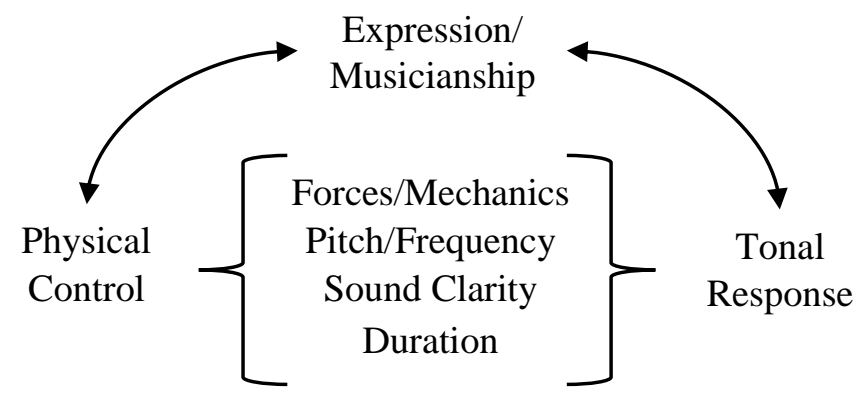

Figure: 17 Overview of Parameters

Table 4 showing the acoustic dependency levels of the perceived quality of sound on physical parameters indicates some evidence that identifies which parameter will be used dominantly to vary the quality. According to Rossing, the pressure to loudness; frequency to pitch; spectrum to timbre and duration measured dominantly depend on each other. Frequency and envelope moderately influence the timbre and the remaining have little to no interactions amongst each other.

Table 4 The acoustic dependency levels of the perceived quality of sound on physical parameters [13]

\begin{tabular}{|c|c|c|c|c|}
\hline \multirow{2}{*}{$\begin{array}{c}\text { PHYSICAL } \\
\text { PARAMETER }\end{array}$} & \multicolumn{4}{|c|}{ PERCEIVED QUALITY } \\
\hline & Loudness & Pitch & Timbre & Duration \\
\hline Pressure & High & Low & Low & Low \\
\hline Frequency & Low & High & Medium & Low \\
\hline Spectrum & Low & Low & High & Low \\
\hline Duration Measured & Low & Low & Low & High \\
\hline Envelope & Low & Low & Medium & Low \\
\hline
\end{tabular}

\subsection{Manufacture of Musical Instruments}

Richard Smith an acoustician and brass instrument maker blind tested ten professional trombonists by replacing brass bells of varied wall thicknesses on the tenor trombone. The players could not distinguish the trombones during the experiment even the mystery one made of pure copper [14]. Therefore, the 
instrument is not limited to one material and may be confined to the available manufacturing capabilities once finished part satisfies the physical parameters for the desired sound. A hand-built instrument is still a marketable item but the factory-built instrument has the advantage of batch numbers and improved consistency with the introduction of precision tooling, computer numerically controlled machines, lasers, and robots. Like all manufacturing processes, inconsistencies do occur especially in material variations. This affects the sound quality and many cases are addressed manually using the techniques from the handbuilt industry [15].

Gershenson's taxonomy was used to categorize the engineering requirements for the end-user, regulatory, corporate, and technical requirements. Table 5 shows the further classification of the categories to assist in the development of the manufacturing processes.

Table 5 Requirements for engineering categories adapted from [16]

\begin{tabular}{|l|l|}
\hline Category & \multicolumn{1}{c|}{ Requirements } \\
\hline End-user & Performance characteristics, usability, aesthetics, and styling \\
\hline Regulatory & Safety, health, environment, and product retirement \\
\hline Corporate & $\begin{array}{l}\text { Marketing, business environment, strategic management, finance, accounting, and } \\
\text { product manufacturing, distribution, support and service, and retirement }\end{array}$ \\
\hline Technical & Product manufacturing, material, and parts availability \\
\hline
\end{tabular}

Prior to fabrication, it is suggested to envisage the ability of the facility, product demand, marketing requirements, engineering procedures and monitoring mechanisms, labour capacity, institution strategy, new product introduction, and customer satisfaction. This will give greater detail in the formation of the business process and ensure the availability of capabilities and competencies to manufacture the product [17].

\subsection{Fuzzy Logic}

Sociology or psychology usually model systems data from a linguistic form, also known as qualitative form. Concepts dealing with human cognition can be a qualitative measure that is naturally communicated nonnumerically. Fuzzy logic allows qualitative data to be described quantitatively in terms of fuzzy numbers or fuzzy sets with semantical relations [18].

\subsection{Multi-Criteria Decision Making (MCDM)}

MCDM is a structured analytic tool that solves problems comprised of unrelated/conflicted discrete data sets. The process identifies and structurally forms the problem components for the development and application of a model to assign an appropriate solution to sort, classify or rank the best solution [19]. To evaluate a musical instrument two MCDM methods were used, Technique of Order Preference by Similarity to Ideal Solution (TOPSIS) and Analytic Hierarchy Process (AHP).

\subsubsection{Technique of Order Preference by Similarity to Ideal Solution (TOPSIS)}

TOPSIS systematically computes the best opportunity from many types and levels of data. This data can be unrelated and allows technical and non-technical information to be used to produce the solution [20].

This method was chosen for its ability to:

- Consistently adapt to varied criteria

- Works well with fewer criteria

- Highlights the dissociate relationship amongst unrelated options 
- Relatively easy to compute

- Works with high numbers of criteria or options

- Adapts to vague and subjective decision-making problems

\subsubsection{Analytic Hierarchy Process (AHP)}

AHP logically resolves issues by evaluating the degree of similarity sourced from persons' belief, mood, inference, and memory through a pairwise comparison [21].

This method was chosen for its ability to:

- Capture the instinctive behavioral patterns formed from experiences

- Uses reasoning and intuition

- Simple pairwise comparison

- Relatively easy to compute

- Capture tangible and intangible attributes

- Work in simple structures

\subsection{Quality Function Development (QFD)}

The QFD framework is used in the design process by translating customer needs into product features. These needs and features are numerically scored, collated and evaluated using the house of quality (HOQ) tool to define the final features of the product [22]. The HOQ is a documented matrix forming a house with rooms and a roof. It shows the matrices ranking the WHATs and HOWs independently and then ranks their relationship against each other as seen in Figure: 2. QFD is applied in product development revealing characteristics of the manufacturing process, trade, and supply strategies. It facilitates an environment measuring the effect of the customer needs which are exhibited on the product features. In general terms, the requirements or 'WHATs' are defined and the solution, 'HOWs' are chosen to produce the 'WHATs' [23]. Another key feature is competitive satisfaction performance, where the strengths and weaknesses of the 'WHATs' and 'HOWs' are measured against existing products [24]. 


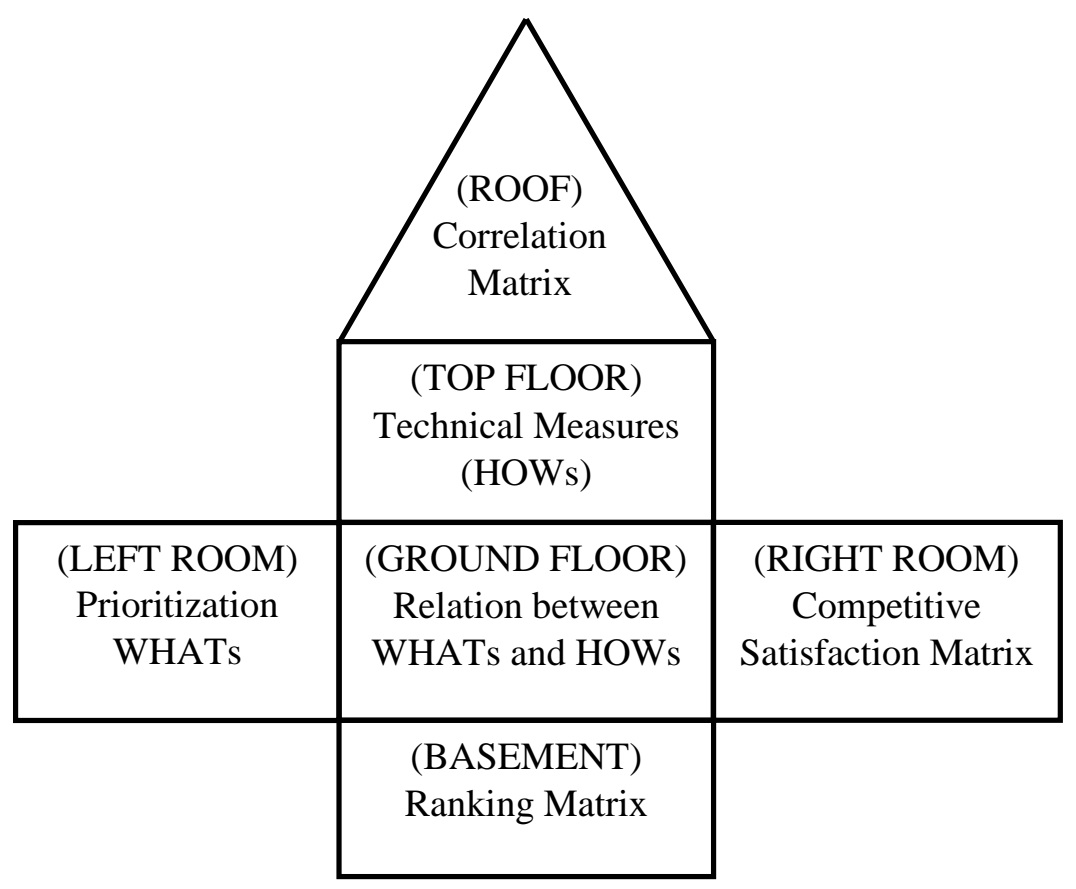

Figure: 18 House of Quality (HOQ) 


\section{Model Development}

The model captures and assesses attributes throughout the re/development and construction of a musical instrument. The standard QFD format ranks the WHATs and HOWs independently and then ranks their relationship against each other. AHP is used twice to perform the independent correlation on the WHATs and HOWs computing the Prioritization Matrix for the WHATs and Correlation Matrix for the HOWs. TOPSIS will replace the QFD method in the Relation Matrix between the WHATs and HOWs.

This model creates a mechanism that introduces various forms and levels of data from technical and nontechnical persons at different levels of competency. The data is collected in a linguistic form and passed through a fuzzy feature to form crisp values. Then the preceding data are combined to formulate the Absolute Weights and Ranking using the original QFD method.

The model is initiated from data WHATs are collected by customers, audience, musicians and engineers and design requirements fed by marketing representatives and engineers to identify and rank the product features. This is then conveyed forward to the next step as seen in Table 6. It combines technical and nontechnical information to ensure both low and high-level data are incorporated into the model. The features on the musical side in relation to the musician and the audience can be identified and used to initiate the model.

Table 6 Integrated QFD Inputs

\begin{tabular}{|c|c|c|c|c|}
\hline & & & \multicolumn{2}{|c|}{ OPERATION PLANNING } \\
\hline & & \multicolumn{2}{|c|}{ PROCESS PLANNING } & \multirow[b]{4}{*}{$\begin{array}{c}\text { Operations \& } \\
\text { Control }\end{array}$} \\
\hline & \multicolumn{2}{|c|}{ PART DEPLOYMENT } & & \\
\hline \multicolumn{2}{|c|}{ PRODUCT DESIGN } & & & \\
\hline $\begin{array}{l}\text { Customer } \\
\text { Requirements }\end{array}$ & $\begin{array}{c}\text { Design } \\
\text { Requirements }\end{array}$ & $\begin{array}{c}\text { Product } \\
\text { Characteristics }\end{array}$ & $\frac{\text { Manufacturing }}{\text { Operations }}$ & \\
\hline $\begin{array}{l}\text { Loudness } \\
\text { Pitch } \\
\text { Timbre } \\
\text { Duration } \\
\text { Musicianship } \\
\text { Physical Control }\end{array}$ & $\begin{array}{l}\text { Pressure } \\
\text { Frequency } \\
\text { Spectrum } \\
\text { Envelope } \\
\text { Expression }\end{array}$ & $\begin{array}{l}\text { End-user } \\
\text { Regulatory } \\
\text { Corporate } \\
\text { Technical }\end{array}$ & $\begin{array}{l}\text { Knowledge } \\
\text { Skill } \\
\text { Facility } \\
\text { Equipment } \\
\text { Material } \\
\text { Utility }\end{array}$ & $\begin{array}{l}\text { Quality } \\
\text { Delivery } \\
\text { Assembly } \\
\text { Schedule } \\
\text { Inspection }\end{array}$ \\
\hline $\begin{array}{l}\text { Sourced from } \\
\text { Audience, } \\
\text { Musicians \& } \\
\text { Engineers }\end{array}$ & $\begin{array}{l}\text { Sourced from } \\
\text { Marketing \& } \\
\text { Engineers }\end{array}$ & $\begin{array}{l}\text { Sourced from } \\
\text { Engineers \& } \\
\text { Entrepreneurs }\end{array}$ & $\begin{array}{l}\text { Sourced from } \\
\text { Engineers \& } \\
\text { Operators }\end{array}$ & $\begin{array}{l}\text { Sourced from } \\
\text { Operators \& } \\
\text { Accountants }\end{array}$ \\
\hline
\end{tabular}

The model will be used separately in each of the four (4) parts of the QFD identified in the following steps:

i. Product Design, the most important step ensuring the market features are all captured in the model. These customer requirements are identified by the audience and musicians to be converted into a set of parameters defining the musical instrument, the design requirements.

ii. Part Deployment, the highly-rated design requirements are then passed through the model to be converted into the physical features of the musical instrument revealing the product characteristics.

iii. Process Planning, the highly-rated product characteristics are then similarly passed through the model to be converted into the manufacturing operations to produce the musical instrument. 
iv. Operation Planning, the highly-rated manufacturing operations are then again passed through the model to be converted into the operations and control criteria for quality assurance [25] [26].

The relations between this Fuzzy QFD TOPSIS AHP Model (illustrated in Figure: 19) and the traditional QFD method can be observed in the description of the steps of the model described below. This is a combination of methods that could be recommended for other applications. The prominent purpose of applying the TOPSIS and AHP methods was to carry out the interrelated and relative comparison functions within the QFD environment. Further, into the research other methods can be considered once a standard reference for the results is found. This will give the opportunity to measure the performance of the model.

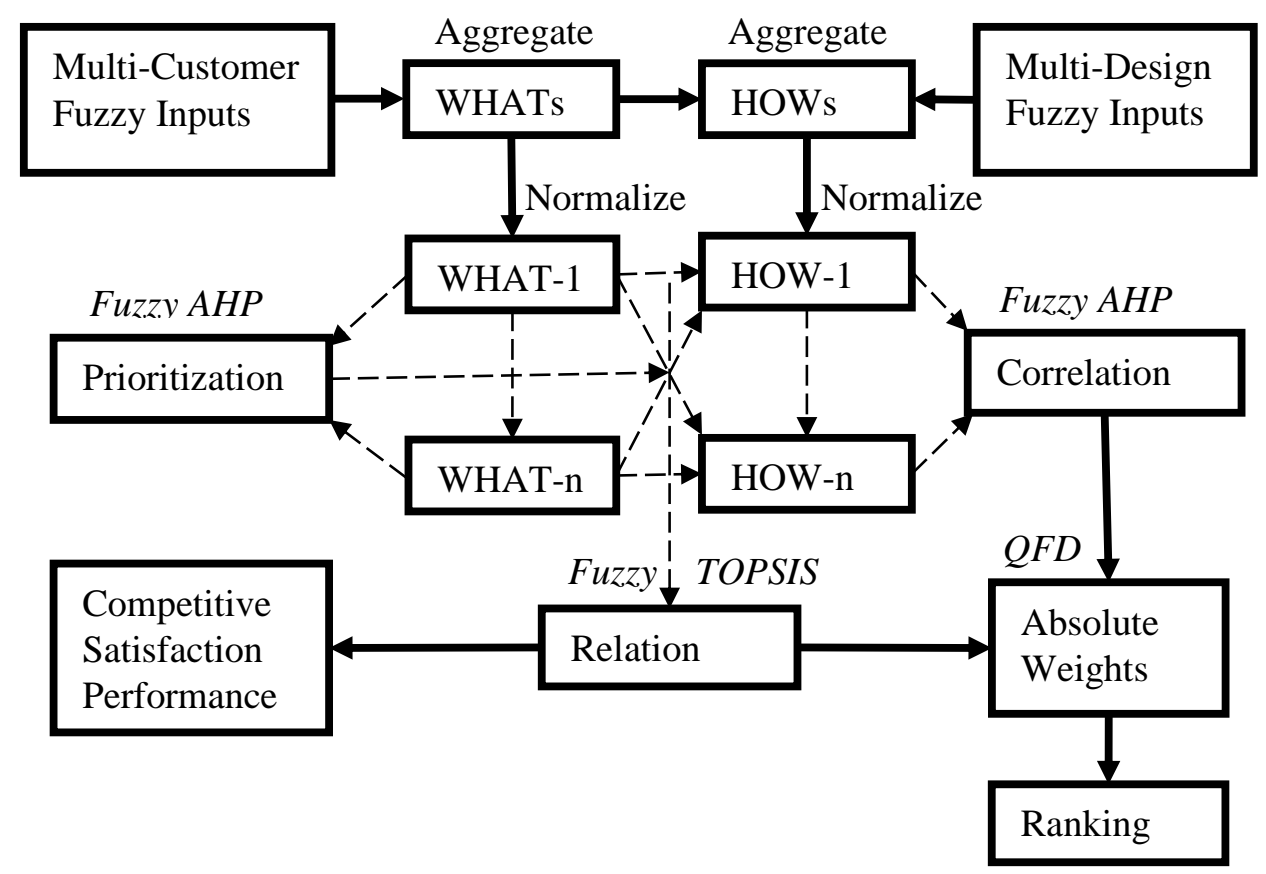

Figure: 19 Fuzzy QFD TOPSIS AHP Model adapted from Bolar et al. [27]

Steps in the Fuzzy QFD TOPSIS AHP Model

i. Multiple groups formed by customers identify and provide fuzzy data for the WHATs

ii. This WHATs data is aggregated and normalized

iii. The normalized WHATs data is prioritized with Fuzzy AHP

iv. Multiple groups formed by designers identify and provide fuzzy data for the HOWs referring to the prioritized WHATs in step iii. above

v. The HOWs data is aggregated and normalized

vi. The normalized HOWs data are correlated with Fuzzy AHP

vii. Both normalized WHATs and HOWs relations are evaluated with Fuzzy TOPSIS

viii. The Competitive Satisfaction Performance is scored by the level of customer satisfaction between the developed product and existing products

ix. The HOWs are ranked with the absolute weights of the correlated Fuzzy AHP and related Fuzzy TOPSIS 


\section{Discussion}

Many researchers have developed models with combined decision-making analytical tools to compute the preferences of previously chosen attributes. Interactions developed through a musical instrument are multidimensional and vary depending on the subject. The attributes for musical instruments are divided between physical and psychological components.

Table 7 Summary of the Fuzzy QFD TOPSIS AHP Model Components [28] [29]

\begin{tabular}{|c|c|c|}
\hline Purpose of Component & Benefits & Limitations \\
\hline $\begin{array}{l}\text { QFD } \\
\text { Creates the environment to } \\
\text { identify and prioritize the } \\
\text { solution HOWs translated } \\
\text { from customer WHATs } \\
\text { sourced from both primary } \\
\text { and secondary data }\end{array}$ & $\begin{array}{l}\text { Collects and processes customer } \\
\text { views. } \\
\text { Most appropriate WHATs are } \\
\text { chosen in the final product } \\
\text { version. } \\
\text { Improves product performance. } \\
\text { Presents data for further } \\
\text { analysis. } \\
\text { Incorporates many disciplines. } \\
\text { Improves interdepartmental } \\
\text { communication. } \\
\text { Reduces initial cost. } \\
\text { Identifies the products and } \\
\text { manufacturing processes in one } \\
\text { method. }\end{array}$ & $\begin{array}{l}\text { Can be complicated. } \\
\text { Takes considerable time. } \\
\text { Large sets of attributes may change } \\
\text { the results. } \\
\text { Challenged with bias or irrelevant } \\
\text { data. } \\
\text { Contradiction not easily resolved. } \\
\text { Difficult to prioritize WHATs and } \\
\text { HOWs with ordinary scales or rates. } \\
\text { WHATs can change over time and } \\
\text { data collected captures the present } \\
\text { state. } \\
\text { Arranging groups for participation } \\
\text { is difficult. } \\
\text { Time, budget and facility } \\
\text { constraints reduce choice to most } \\
\text { appropriate. }\end{array}$ \\
\hline $\begin{array}{l}\text { Fuzzy } \\
\text { Provides a compatible path } \\
\text { to process the quantitative } \\
\text { and qualitative data }\end{array}$ & $\begin{array}{l}\text { Allows subjectively vague data. } \\
\text { Simultaneously retrieve data } \\
\text { from different levels of groups. } \\
\text { Captures partial natural humane } \\
\text { feelings produced by uncertain } \\
\text { systems. } \\
\text { Quantifies common sense. } \\
\text { Linguistic variables. }\end{array}$ & Adds more complex calculations. \\
\hline $\begin{array}{l}\text { TOPSIS } \\
\text { Determines and ranks the } \\
\text { interrelations between the } \\
\text { WHATs and HOWs }\end{array}$ & $\begin{array}{l}\text { Ranking of real situations. } \\
\text { Measure relative distances to } \\
\text { positive ideal solution and } \\
\text { negative ideal solutions. } \\
\text { Process non-optimal alternatives. }\end{array}$ & Not compatible with crisp values. \\
\hline $\begin{array}{l}\text { AHP } \\
\text { Determines and ranks the } \\
\text { isolated individual relations } \\
\text { on the WHATs and HOWs }\end{array}$ & $\begin{array}{l}\text { Pairwise comparison. } \\
\text { Computation tests the validity of } \\
\text { internal ranks. }\end{array}$ & $\begin{array}{l}\text { More complex computations. } \\
\text { Unbalanced scale used. } \\
\text { Unable to process natural forms of } \\
\text { uncertainty and vagueness. }\end{array}$ \\
\hline
\end{tabular}


Traditional engineering design has established many methods of making choices for physical components. The psychological component may be less developed potentially losing relevant data hindering the assurance of a satisfied customer.

Capturing the full view of the customer involves a model that ensures the simultaneous compatibility of data derived from tangible and non-tangible features. Tangible features can be assessed with the accepted traditional engineering design principles. The psychological component assesses an individual's affection, cognition, and emotional state. Table 7 shows the components, highlighting and revealing some key limitations of the symbiotic relationship found in the Fuzzy QFD TOPSIS AHP Model.

The musical relationship of the physical parameters with the perceived qualities was discovered to be high for pressure vs loudness, frequency vs pitch, spectrum vs timbre and duration measured vs duration. This provides a datum to monitor the Product Design component in the QFD to ensure the solution is reliable. Finding a pressure ranking that is higher with the pitch over loudness is inconsistent. The assessment may be unreliable and should be reviewed to rectify or at least justify this solution.

\section{Conclusions}

The contents of this paper introduce the portion of a study that involves the redevelopment of a musical instrument. It builds on a structure that identifies requirements for a musical instrument, simultaneously incorporating the views of musicians, audience members, manufacturers, and entrepreneurs. The development or modification stage of the instrument requires that the majority of the features, WHATs throughout the four QFD steps should satisfy its stakeholders. A Fuzzy QFD MCDM environment increases the opportunity to identify and provide acceptable decisions throughout the manufacturing life cycle of the product. This Fuzzy QFD TOPSIS AHP Model accepts qualitative data, measures the relations and ranks both WHATs and HOWs individually and against each other. It also captures the non-technical qualities of the musical instrument at different levels and a variety of sources, reducing the uncertainty gap to have an all-inclusive satisfaction level.

In the next stage of this project, a case study will be developed on a common musical instrument to test the model. This should validate the model results and determine any deficiencies involving bias. The effects of capturing the psychological components in the model are also an important feature to compare with a traditional QFD. The similarity between AHP and TOPSIS should also be compared to ensure and correct any discrepancies that would affect the overall results and objectives. 


\section{References}

[1] C. Fritz, D. Dubois. "Perceptual evaluation of musical instruments: State of the art and methodology." Acta Acustica united with Acustica 101, no. 2 (2015): 369-381.

[2] M.M. Aghdam, I. Mahdavi, B. Shirazi, J. Vahidi, 2015. House of quality improvement by new design requirements generation. International Conference on Industrial Engineering and Operations Management.( pp. 1-9). IEEE.

[3] L. Li, F. Liang, Q. Qin, X. Li. 2016. Behavioral multi-criteria decision making with multi-granularity 2-dimension fuzzy linguistic variables. Chinese Control and Decision Conference. (pp. 5688-5694).

[4] Y. Z. Chen and E. W. T. Ngai. A fuzzy QFD program modelling approach using the method of imprecision. International Journal of Production Research 46 no. 24, (2008) 6823-6840.

[5] U. Widiastuti, A.S. Sembiring, M. Hasbullah. 2019. Selection standardization and musical instruments assessment of music instruments preparation subject in music education study program of UNIMED. International Journal of Education, Learning and Development (pp. 51-62). ECRTD.

[6] T. Kvifte. What is a musical instrument? Swedish Journal of Music Research 90, no. 1, (2008) 45-56.

[7] U. G. Wegst. Bamboo and wood in musical instruments. Annual Review of Materials Research 38 no. 1 , (2008) 323-349.

[8] M. Campbell. Objective evaluation of musical instrument quality: A grand challenge in musical acoustics. Journal of the Acoustical Society of America 19 no. 1, (2013).

[9] P. Shinde, V. Javeri, and O. Kulkarni. Musical Instrument Classification using Fractional Fourier Transform and KNN Classifier. International Journal of Science, Engineering and Technology Research 3 no. 5 , (2014).

[10] J. Villegas and M. Cohen. Roughness Minimization Through Automatic Intonation Adjustments. Journal of New Music Research (2010) 75-92.

[11] R. J. Zatorre and I. Peretz, 2001. The biological foundations of music. New York Academy of Sciences. [12] G. Paine. New Musical Instrument Design Considerations. IEEE MultiMedia 20 no. 4, (2013) 76-84.

[13] T. D. Rossing, 2002. The science of sound. Addison Wesley.

[14] D. M. Campbell. Evaluating musical instruments. Physics Today 67, no. 4, (2014) 35-40.

[15] P. Dumond, 2010. Towards improving the manufactured consistency of wooden musical instruments through frequency matching. ProQuest Dissertations Publishing.

[16] K. S. Rounds, J. Cooper. Development of product design requirements using taxonomies of environmental issues. Resarch in Engineering Design 13 no. 2, (2002) 94-108.

[17] J. Mills, K. Platts, and M. Gregory. A framework for the design of manufacturing strategy processes. International Journal of Operations \& Production Management 15 no. 4, (1995) 17-49.

[18] M. Sugeno and T. Yasukawa. A fuzzy-logic-based approach to qualitative modeling. IEEE Transactions on Fuzzy Systems 1 no. 1, (1993) 7-31.

[19] V. Belton, 2002. Multiple criteria decision analysis : An integrated approach. Kluwer Academic Publishers.

[20] S. Opricovic and G.H. Tzeng. Compromise solution by MCDM methods: A comparative analysis of VIKOR and TOPSIS. European Journal of Operational Research 156 no. 2, (2004) 445-455.

[21] T. L. Saaty, 1994. Fundamentals of decision making and prority theory with the analytic hierarchy process. RWS Publications.

[22] U. Belhe and A. Kusiak. The house of quality in a design process. International Journal of Production Research 34 no. 8, (1996) 2119-2131.

[23] G. Z. Jia and M. Bai. An approach for manufacturing strategy development based on fuzzy-QFD. Computers \& Industrial Engineering 60 no. 3, (2011) 445-454.

[24] J. P. Ficalora, 2010. Quality function deployment and Six Sigma : A QFD handbook. Prentice Hall.

[25] M. Pullman, 1998. Effective product and process development using quality function deployment: Methods, Tools, and Technologies. Wiley. 
[26] H.B. Yan and T. Ma. A group decision-making approach to uncertain quality function deployment based on fuzzy preference relation and fuzzy majority. European Journal of Operational Research 241 no. $3,(2015)$ 815-829.

[27] A. Bolar, S. Tesfamariam, and R. Sadiq. Management of Civil Infrastructure Systems: QFD-Based Approach. Journal of Infrastructure Systems 20 no. 1, (2014).

[28] M. Moayeri, A. Shahvarani, M. H. Behzadi, and F. Hosseinzadeh-Lotfi. Comparison of Fuzzy AHP and Fuzzy TOPSIS Methods for Math Teachers Selection. Indian Journal of Science and Technology 8 no. 13, (2015).

[29] İ. Ertuğrul. Comparison of fuzzy AHP and fuzzy TOPSIS methods for facility location selection. International Journal of Advanced Manufacturing Technology 39 no. 7, (2008) 783-795. 